\title{
Human action on structures: comparison between numerical load models and experimental data
}

\author{
[P. Rubio, J. Fernández, L. Hermanns, A. Fraile, E. Alarcón ]
}

\begin{abstract}
Modelling of human-induced loads has been proved to be very difficult as we can see in several approaches of varying complexity that have been presented in the literature. Crowd induced dynamic loading in large structures, such as gymnasiums or stadiums, is usually modelled as a series of harmonic loads which are defined in terms of their Fourier coefficients. Different values of these Fourier coefficients that were obtained from full scale measurements can be found in codes. In this paper, a study of loads generated by different human actions (jumping, walking and dancing) is presented. A comparison between experimental data measured with instrumented insoles and numerical data obtained with numerical models has been carried out. Tests have been performed on a structure designed to be a gymnasium, which has natural frequencies within that range of the excitation frequencies.
\end{abstract}

Keywords - human induced load, dynamic test, walking load, jumping load, dancing load, full scale test.

\section{Introduction}

The interest for modelling of human induced loads on structures has been recurrent since the first accidents on suspension bridges in the nineteenth century like Broughton (1831) in the U.K. or Angers (1850) in France. The use of new materials allowing the design of slender structures, the simultaneous interest in the structural serviceability performance and accidents such as during the opening ceremony of the London Millenium Footbridge (10 June 2000) made it mandatory to carry on and in-depth analysis of the equivalent actions to be used in the numerical analysis of structures.

One of the first summaries was due to Bachman [1] et al. where the modelling of individual loads was fruitfully studied.One of the most influential research, conducted by Lenzen and Murray [2] as early as 1969, suggested the use of the so-called "heel drop test" for assessing the vibration susceptibility of light floors under walking loads. Although the general applicability of their results has been questioned its influence on National Codes (like the current Spanish "Código Técnico de la Edificación") has been extensive.

Current research authors are Ebrahimpour, Pernica, Allen, Ellis [4]. More recently interesting contributions are due to Ellis and Ji [5] and Sim [6]. Also important are European research projects and the publication of Steel Construction Institute (SCI) Guide P354 [7] incorporating new results such as the reduction factors for the Fourier coefficients representing the crowd activities has been of particular interest.
In this work, a comparison between experimental measurements from dynamic tests and numerical results has been carried out. The numerical results have been obtained by means of the SCI model and data measured with instrumented insoles calibrated with a force plate.

\section{Dynamic action models}

In the current study, numerical load models proposed by the SCI in the document SCI P354 "Design of Floors for Vibration: A New Approach" are used to simulate the next human actions:

- Jumping

- Walking

- Dancing

In the following sections the different models will be briefly described.

\section{A. Jumping and dancing model}

In the jumping model, described in SCI P354 guide, the acting load follows the procedure explained by Ellis that is based on the typical Fourier series used to represent periodic human loading:

$$
F(t)=W\left(1+\sum_{j=1}^{3} \alpha_{j} \sin \left(\omega_{j} t+\phi_{j}\right)\right)
$$

where $\mathrm{W}$ is the weight of the jumpers, $\omega_{\mathrm{j}}$ is $\mathrm{j}$ times the jumping frequency, $\phi_{\mathrm{j}}$ is the phase lag of the jth term and $\alpha_{\mathrm{j}}$ is the Fourier coefficient (or dynamic load factor) of the jth term.

The load-time history of dancing-type loads is based on the assumption that a high contact force for a period of time, knowing as contact period, is followed by zero force when the feet leave the floor. Therefore, the load-time function is expressed by a sequence of semi-sinusoidal pulses. Different contact ratios characterise different rhythmic activities and the lower value of the contact ratio entails more vigorous activity. For analysis, the load function may be expressed as a Fourier series as equation (1)

For both models, $\alpha_{j}$ and $\phi_{j}$ values of the jth term are shown in Table I. 
TABLE I. FOURIER COEFFICIENTS AND PHASE LAGS FOR DIFFERENT CONCTACT RATIOS

\begin{tabular}{|c|c|c|c|c|c|}
\hline \multicolumn{6}{|c|}{ Fourier coefficient and phase lag for $h^{\text {th }}$ harmonic } \\
\hline & & & $h=1$ & $h=2$ & $\mathbf{h}=\mathbf{3}$ \\
\hline \multirow{2}{*}{$\alpha_{c}=2 / 3$} & \multirow{2}{*}{$\begin{array}{c}\text { Low impact } \\
\text { aerobics }\end{array}$} & $\alpha_{\mathrm{h}}$ & $9 / 7$ & $9 / 55$ & $2 / 15$ \\
\hline & & $\phi_{\mathrm{h}}$ & $-\pi / 6$ & $-5 \pi / 6$ & $-\pi / 2$ \\
\hline \multirow{2}{*}{$\alpha_{c}=1 / 2$} & \multirow{2}{*}{$\begin{array}{c}\text { High impact } \\
\text { aerobics }\end{array}$} & $\alpha_{\mathrm{h}}$ & $\pi / 2$ & $2 / 3$ & 0 \\
\hline & & $\phi_{\mathrm{h}}$ & 0 & $-\pi / 2$ & 0 \\
\hline \multirow{2}{*}{$\alpha_{c}=1 / 3$} & \multirow{2}{*}{ Normal jumping } & $\alpha_{\mathrm{h}}$ & $9 / 5$ & $9 / 7$ & $2 / 3$ \\
\hline & & $\phi_{\mathrm{h}}$ & $\pi / 6$ & $-\pi / 6$ & $-\pi / 2$ \\
\hline
\end{tabular}

$\alpha_{\mathrm{j}}$ and $\phi_{\mathrm{j}}$ values of the $\mathrm{jth}$ term shown in Table I are appropriate for small groups of individuals engaged in rhythmic activities. For large groups, the lack of coordination between participants can be taken into account replacing the first three Fourier coefficients in Table I by the following:

$$
\begin{aligned}
& \propto_{1}=1.61 p^{-0.082} \\
& \propto_{2}=0.94 p^{-0.24} \\
& \propto_{3}=0.44 p^{-0.31}
\end{aligned}
$$

\section{B. Walking model}

The forcing function from a walking activity is assumed to be perfectly periodic. This function can be represented by the first four harmonic components, calculated from Fourier analysis. The amplitude of the harmonic force is given by:

$$
F_{h}=Q\left[\sum_{h=1}^{4} \alpha_{h} \sin \left(2 \pi h f_{p} t+\varphi_{h}\right]\right.
$$

where $\mathrm{Q}$ is the weight of the average walker.

The Table II shows the Fourier coefficients which may be

\begin{tabular}{|c|c|c|c|}
\hline Harmonic $\mathrm{h}$ & $\begin{array}{l}\text { Excitation frequency } \\
\text { range } \mathrm{hf}_{\mathrm{p}}(\mathrm{Hz})\end{array}$ & $\begin{array}{c}\text { Design value of } \\
\text { coefficient } \\
\alpha_{h}\end{array}$ & $\begin{array}{c}\text { Phase } \\
\text { angle } \varphi_{\mathrm{h}}\end{array}$ \\
\hline 1 & $1.8-2.2$ & $0.436(\mathrm{fp}-0.95)$ & 0 \\
\hline 2 & $3.6-4.4$ & $0.006(\mathrm{fp}+12.3)$ & $-\pi / 2$ \\
\hline 3 & $5.4-6.6$ & $0.007(\mathrm{fp}+5.2)$ & $\pi$ \\
\hline 4 & $7.2-8.8$ & $0.007(\mathrm{fp}+2)$ & $\pi / 2$ \\
\hline
\end{tabular}
used for steady-state design.

TABLE II. FOURIER COEFFICIENTS AND PHASE LAGS FOR DIFFERENT FREQUENCY RANGES

\section{Measuring system}

The instrumentation consists on an in-shoe pressure distribution measurement device. The system, developed by Novel, is designed for a variety of applications, such as medical, ergonomic, biomedical testing scenarios and research settings. Each insole is composed of capacitive sensors.

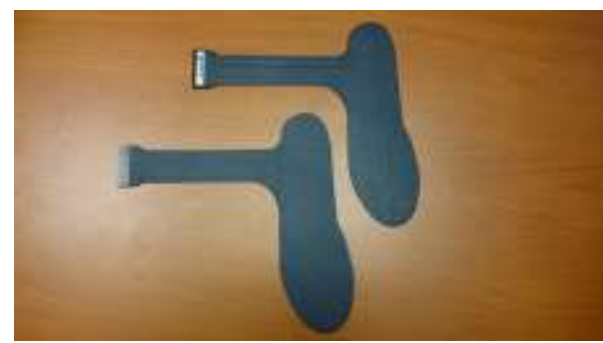

Figure 1. Instrumented insoles.

The calibration was carried out by a comparison between the load time histories registered by a force plate and the insole system. Initial static calibration of the force plate and the insole were accomplished to check the validity of data. Once the static load is known, the individual who wears the insole starts jumping on the plate. Both measurements were carried out with each instrumentation simultaneously and a comparison of forces measured from both force plate and pedar insoles gave a precise relationship between their load profiles (Figure 1).

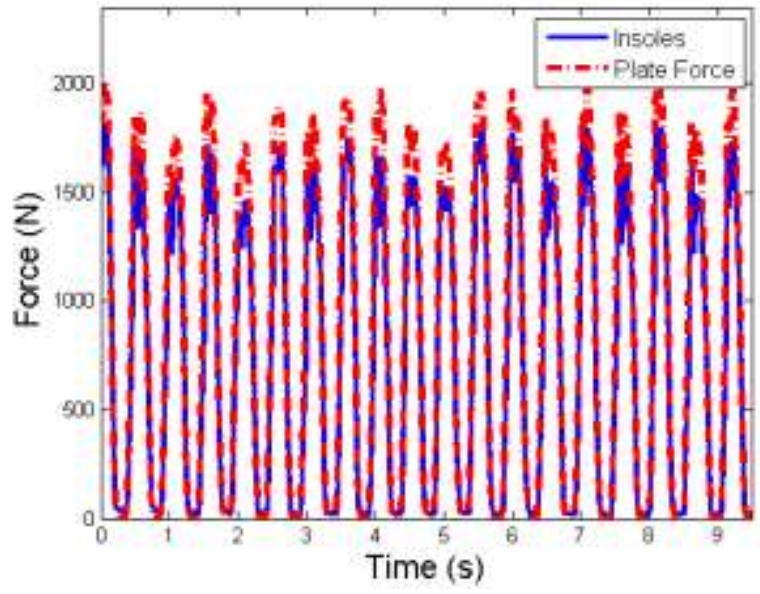

Figure 2. Validation of the insoles with the plate force.

The force plate provides a more accurate measurement in static and out of contact scenarios because of the sway of the shoe.

\section{Testing}

Generally, the testing is performed on platforms or structures that can be considered rigid because their natural frequencies are higher than the excitation frequencies associated with crowd loading.

In this paper, we shall present the testing done on a structure designed to be a gymnasium, which has natural frequencies within that range.

Three human actions have been tested with the aid of the insoles: jumping, walking and dancing test.

\section{A. Jumping test}

An individual jumped at a range of frequencies between 1 and $3 \mathrm{~Hz}$. The targeted frequency was set with a metronome in order to help the jumper to jump at the established frequency. 


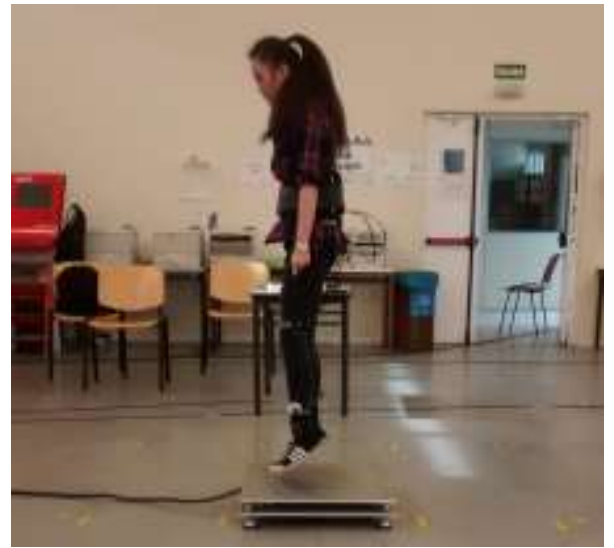

Figure 3. Jumping test.

\section{B. Walking test}

In this case, the span of the pace was set instead of the frequency of the activity. In this way, a path was built with the points where the walker must tread on. The length of each step was chosen according to the complexion of the subject.

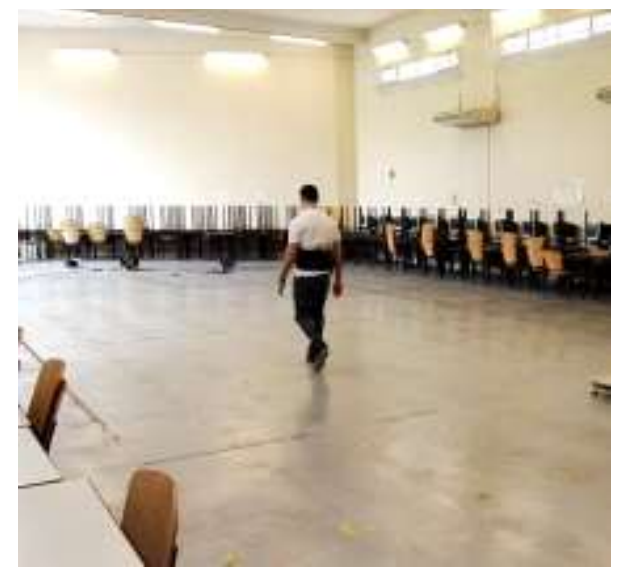

Figure 4. Walking test.

\section{Dancing test}

So as to analyse the dance-type, a test in an ordinary dancing class was carried out. Two participants with different types of shoes wore the insoles.

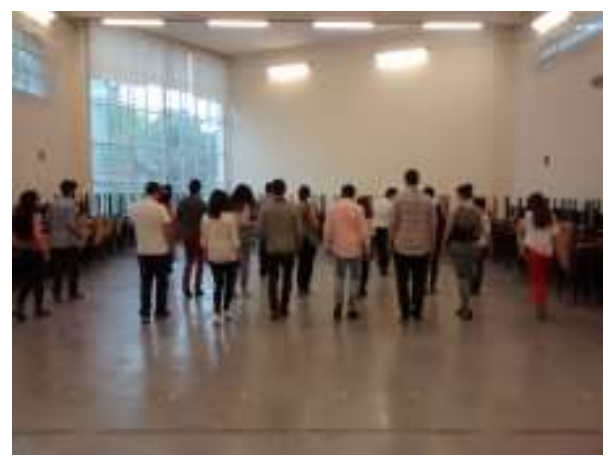

Figure 5. Dancing test.

One of the volunteers was a man, who wore boots and the other one was a woman with high-heels. This represents the two most common profiles in dance activities.

\section{v. Experimental verification of load model}

The analytical models for jumping, walking and dancetype loads are described in part II. In order to assess the accuracy of this load models, some measurements obtained from the data registered by the insoles, are compared with the analytical models.

\section{A. Jumping loads}

The following plot shows the comparison between the analytical model proposed and the measurements of the insoles at a frequency of $2 \mathrm{~Hz}$ :

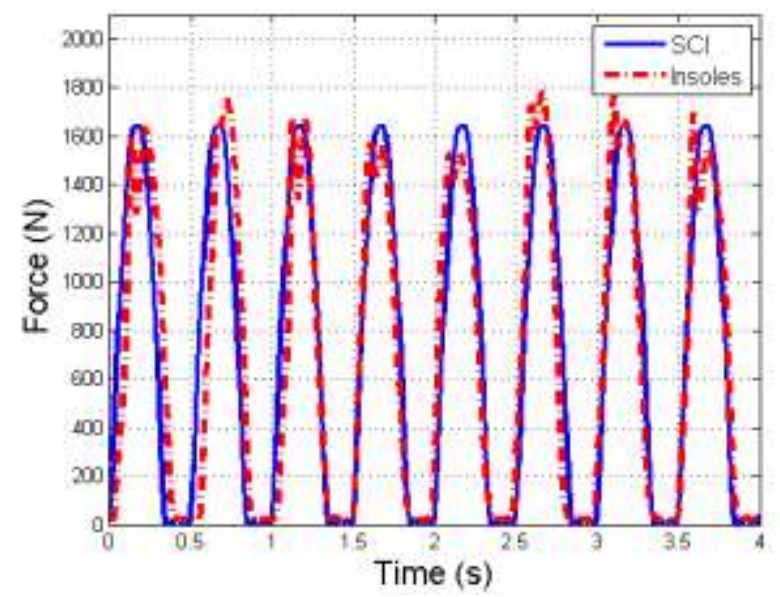

Figure 6. Jumps at $2 \mathrm{~Hz}$. Comparison between SCI model and insoles.

The load represents the total force in the floor, this is to say, the sum of the data of either insole.

The experimental data fits with the model proposed. In this case, both feet strike against the floor at the same time. Therefore, they present zero values between jumps.

In Table III we can see the comparison between experimental and numerical parameters that characterise the activity. As a whole, the mean of the time history load is equal to the weight of the jumper as the analytical model proposes.

TABLE III. COMPARISON BETWEEN LOADS PARAMETERS AT 2HZ

\begin{tabular}{|c|c|c|c|}
\hline Load & Mean $[\mathrm{N}]$ & Contact ratio & $\begin{array}{c}\text { Impact } \\
\text { factor }\end{array}$ \\
\hline SCI & 702 & $2 / 3$ & 2.32 \\
\hline Insoles & 704 & 0.7 & 2.38 \\
\hline
\end{tabular}

The main difference between jumps stays in the frequency of the activity. As we can see in the graph below, jumps at a frequency below $2 \mathrm{~Hz}$ generate a characteristic double hump profile. 


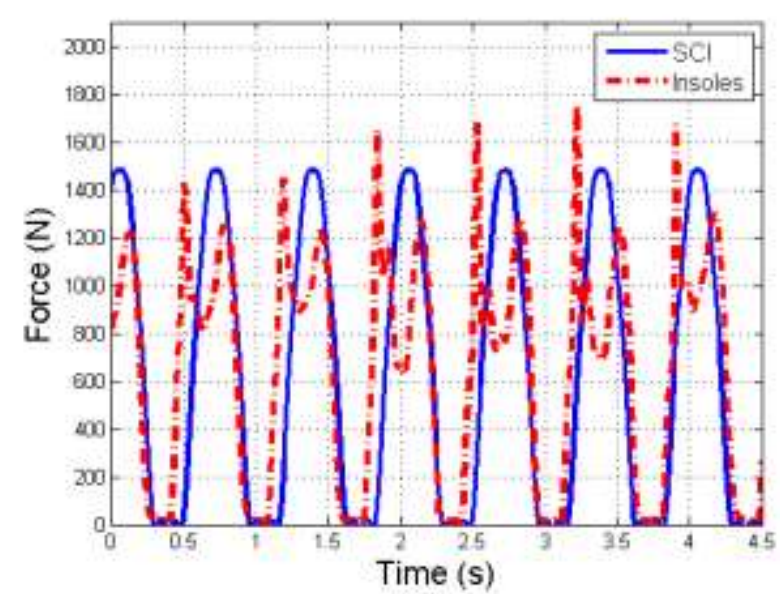

Figure 7. Jumps at $1.5 \mathrm{~Hz}$. Comparison between SCI model and insoles.

The plot above shows a jumping test at a frequency of $1.5 \mathrm{~Hz}$. In this scenario, the terms that characterise the load fits with the measurements data but the load profile presents sensible differences owing to the double hump profile.

TABLE IV. COMPARISON BETWEEN LOADS PARAMETERS AT $1.5 \mathrm{HZ}$

\begin{tabular}{|c|c|c|c|}
\hline Load & Mean $[\mathrm{N}]$ & Contact ratio & $\begin{array}{c}\text { Impact } \\
\text { factor }\end{array}$ \\
\hline SCI & 633 & $2 / 3$ & 2.35 \\
\hline Insoles & 640 & 0.69 & 3.2 \\
\hline
\end{tabular}

\section{B. Walking loads}

In this case, the analytical load represents the total force in the floor, not each tread separately. Consequently, the total force presented in Fig.7 corresponds to the sum of the force data in each insole.

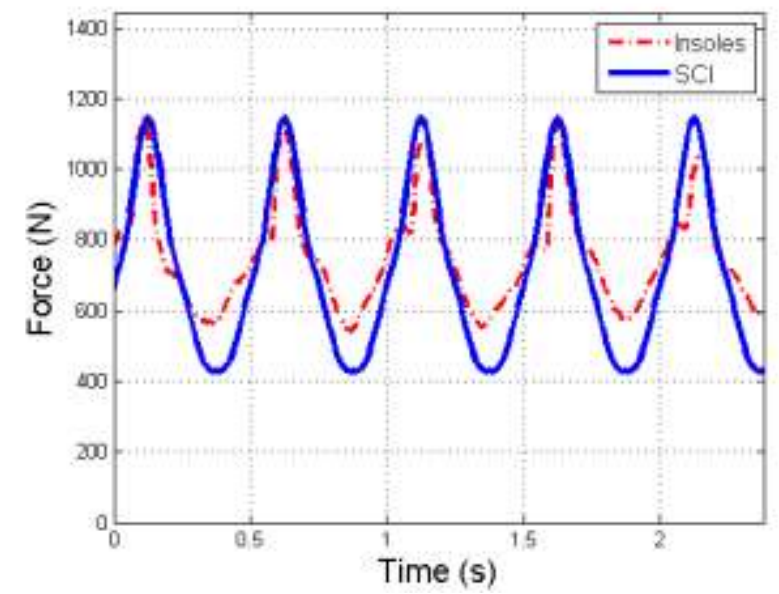

Figure 8. Walking load. Comparison between SCI model and insoles measurement.

The maximum occurs when the pace of each foot overlaps and the load owing to the heel strike and the toe-off instant of the pace cycle is coincident.

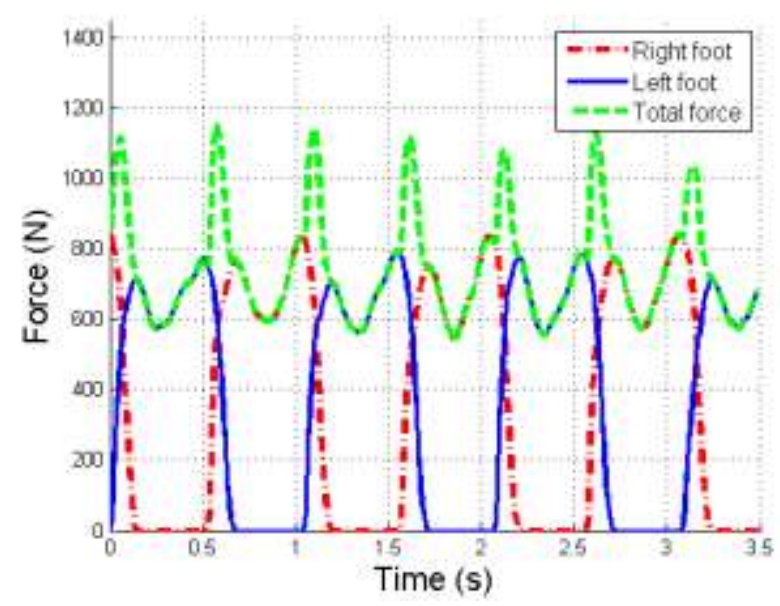

Figure 9. Walking load. Pace overlap and total force.

The experimental results show that the mean of the whole time history is equal to the weight of the walker.

The load profile of separate foot is performed in other texts and it is out of the aims of this study.

\section{Dancing loads}

The chief difference between the data and the analytical function is that the time history fits better with each foot independently instead of the sum of both feet.

The graph below displays the load profile of one foot registered by the instrumented insoles versus the SCI analytical model.

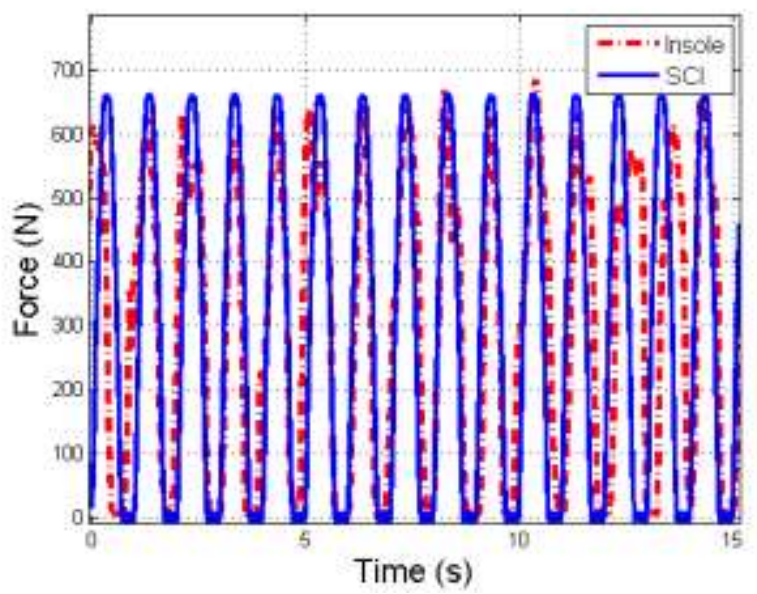

Figure 10. Dancing load. Comparison between one insole data and one foot SCI model.

The dance-type load proposed by SCI is a variety of jumps which fits better with those dances that are composed with jumps. Nevertheless, the dance tested in this study is a load alongside the walking and the jumping loads. Because of that, there is an overlap at each step that causes that there weren't periods without force exerted against the floor.

The following graph shows the overlapping between steps. 


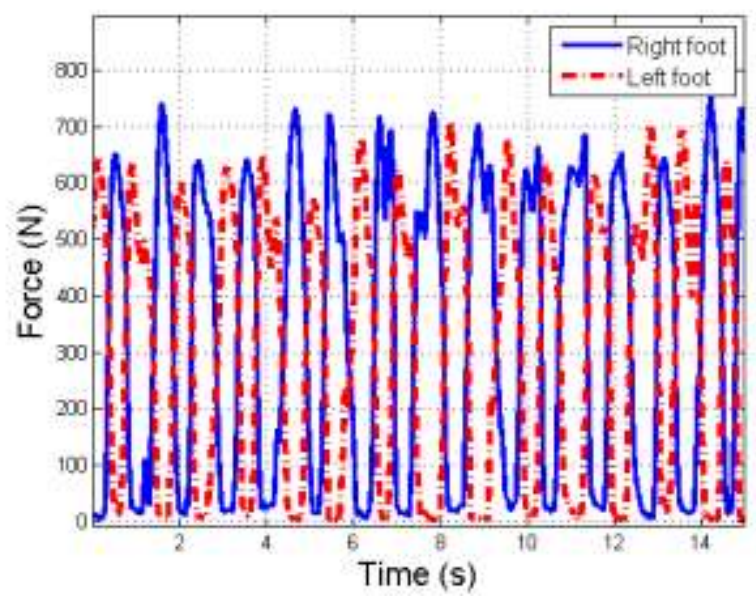

Figure 11. Dancing load. Insoles measurements along the dance class.

As far as the graph below is concerned, each foot can be modeled as an individual jumper whose weight is the half of the total weight as is shown in Figure 11 and there are an overlap at each step as we could see in walking activities

\section{vi. Conclusions}

A comparison between measurements from dynamic tests and numerical results has been carried out

The parameters which characterize the load in the model proposed proposed by the SCI in the document SCI P354 "Design of Floors for Vibration: A New Approach" fits closely with the experimental data.

The mean of the data registered is equal to the static weight of the subject.

Both models, the dance and the jump model, represent the total force acting on floor, which is the sum of the insoles data. The difference between them is that the walking model presents an overlap in each step.

The dance-type load model fits with the force generated by each foot independently.

The instrumented insoles are a good tool to measure the human actions on structures and to developed empiric load models.

\section{References}

[1] Bachmann,H. and Ammann,W. (1987) "Vibrations in Structures Induced by man and machines" IABSE

[2] Lenzan,K.H. and Murray,T.M.(1969):"Vibration of steel Beam Concrete Slab Floor Systems",Repp.29. Depart.Civil Eng. University of Kansas.

[3] Ellis,B.R.(2000) "On the response of long span floors to walking loads generated by individuals and crowds". The structural engineer,78(10), May, 17-25.

[4] Smith,J.W. "Human-induced vibrations" Chapt. 7 in "Dynamic Loading and Design of Structures" Ed. A.J.Kappos, Spon Press (2002)

[5] Ellis,B.R. and Ji,T (2004) "Loads generated by jumping crowds;numerical modelling". The structural Engineer 82(17), 35-40

[6] Sim J.H.H. (2006) "Human-structure interaction in cantilever grandstands" Ph.D. Thesis. University of Oxford .

[7] Steel Construction Institute (2007) "Design of floors for vibration :A New Approach". SCI P 354. 